\title{
IPCC flooded by criticism
}

\section{Climate body slammed for errors and potential conflicts of interest.}

Just over two years after winning the Nobel Peace Prize, the United Nations panel on climate change is undergoing a period of soul-searching.

The Intergovernmental Panel on Climate Change (IPCC) has always been a target for climate-change sceptics. In recent weeks, however, criticism has mounted and the panel admitted to a glaring error in its last comprehensive report, released in 2007, which says that Himalayan glaciers are likely to melt completely by 2035 (see Nature 463, 276-277; 2010). On top of that, its chairman, Rajendra Pachauri, is under pressure to resign because the institute he directs, the Energy and Resources Institute in New Delhi, has ties with companies that could benefit from climate policies.

In response, many climate scientists - including a number already involved in the next IPCC assessment, due in 2014 - have been putting forward ideas about how the panel might reconsider its rules and procedures. The hope is to reduce errors in the final product and create policies on potential conflicts of interest.

The IPCC had already planned for the next assessment report, known as AR5, to follow the same basic outline as its last one, with three working groups to tackle three areas of interest: the physical science of climate change, the impacts such change is likely to have and how these might be mitigated. There are two review editors for each chapter and the whole thing will be checked before publication, first by expert reviewers and then by governments. Governments and scientific organizations around the world are looking for people to serve as authors and reviewers; nominations are due by 12 March.

In addition to the Himalayan glacier error, the panel has been accused of saying that climate change has caused an increase in economic losses from extreme weather; the IPCC last week refuted that allegation, saying that a study in one part of the report had been taken out of context. Others have challenged the source of an estimate contained in the report that up to $40 \%$ of the Amazonian rainforest "could react drastically" to reduced rainfall.

Those involved in the process say it works well. "The IPCC is a bottom-up process in which hundreds of scientists dedicate their time on a voluntary, unpaid basis to provide an assessment of climate science," says Thomas Stocker of the University of Bern, co-chair of AR5's first working group, on the physical science of climate change. "This

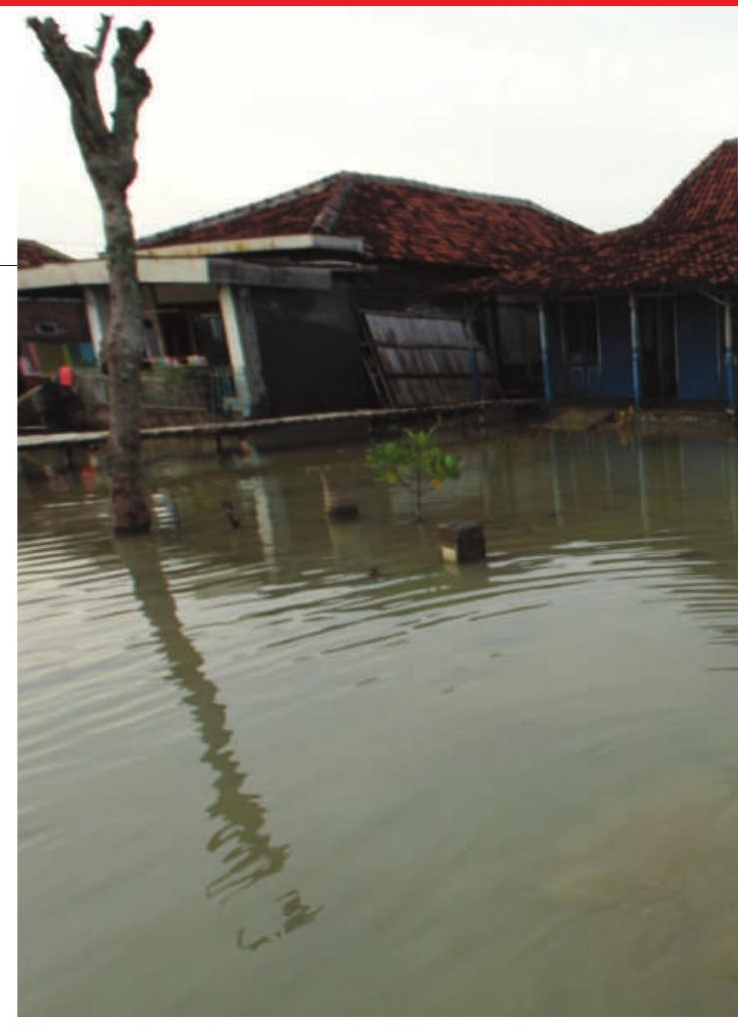

The group's next assessment will focus on the socio-economic effects of climate change.

model has been extremely successful."

"In my view, the IPCC's institutional structures and processes are very strong," adds Pachauri, who says he will not step down as chairman. "What we have to do is to ensure full and complete compliance with the procedures while preparing IPCC's assessment reports."

Others say there is room for improvement. Kevin Trenberth of the National Center for Atmospheric Research in Boulder, Colorado, a lead author of the 2007 report, says that critics

\section{Project set to map marks on genome}

PARIS

At one time, sequencing the whole human genome seemed almost impossible. But even as it was being completed, biologists were realizing that the genes encoded within it would reveal little about what makes each of us unique.

By 2003, it was clear that the true key to understanding our differences was more likely to be found in epigenomics - the reversible chemical modifications to DNA and its associated proteins that determine when genes can be expressed. And epigenomic studies could open up new research avenues in cancer and other complex diseases.

So it was with some fanfare that top biologists launched the

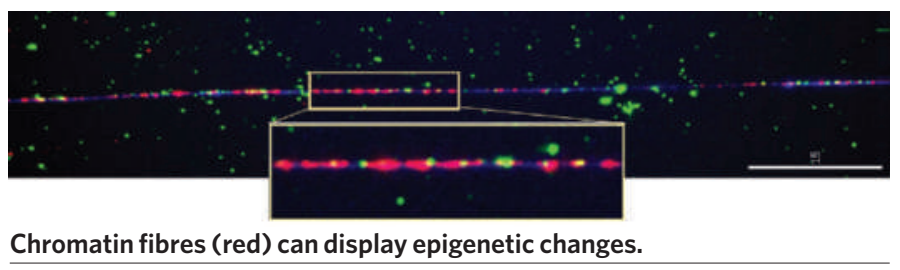

International Human Epigenome Consortium (IHEC) in Paris last week, a global consortium that aims, as its first phase, to map 1,000 reference epigenomes within a decade.

"Epigenomes are changeable, programmable and will feed us the bottom line on how the genome works," says Rob Martienssen of Cold Spring Harbor Laboratory in New York, a member of the consortium's steering committee. "IHEC is an exciting prospect." the European Commission, which in July will publish a call for proposals for a $€ 30$-million (US\$42-million) epigenetics consortium, including a large component for reference epigenomes. Representatives from Canada, France, Germany and severa Asian countries voiced interest at the launch in joining IHEC.

The consortium faces a much greater challenge than did the Human Genome Project when it was launched in 1990. "The human genome is singular and finite, but the human epigenome is almost infinite - the epigenome changes in different states and different tissues," says Philip Avner of the Pasteur Institute in Paris, a member of IHEC's steering committee.

Epigenomics is indeed a complex 
